\title{
Fatality in a body packer: the first reported case in Saudi Arabia
}

\author{
Dalia Alsaif* $\mathbb{D}^{*}$, Salah Ali Almoghannam, Osama M. Almadani and Magdi Kharoshah
}

\begin{abstract}
Background: Body packers use different methods and materials to pack drugs inside their bodies. These could be simple or sophisticated to ensure a successful transfer or concealment of the drug with minimal risk to the packer. Different drugs were reported with cocaine and heroin being the most common. The packer presents to health facilities whenever they develop complications like drug leakage or intestinal obstruction, or they can be detected after a fatal event as an incidental finding in autopsy.

Case presentation: A body packer who was in detention suffered pain and died shortly after that. The autopsy not only revealed severe coronary atherosclerosis but also unveiled 10 rubber packages filled with methamphetamine and cannabis, and one package was found ruptured in the mouth. Toxicological analysis showed a blood level of methamphetamine $3.66 \mathrm{mg} / \mathrm{L}$ which was considered a cause of death. While methamphetamine was reported in cases of body packers, cannabis is rarely concealed by body packers for several reasons including its cost compared to the risk of packing.

Conclusions: This is the first reported case of fatality in body packers in Saudi Arabia and Arab countries. This should put into consideration the need for screening suspicious cases who are involved or suspected to be involved with drugs. Effective screening in specific facilities is needed to reduce fatalities and at the same time lowering drug smuggling.
\end{abstract}

Keywords: Body packer, Amphetamine, Cannabis, Postmortem redistribution

\section{Background}

Body packing is a rising problem with increased drug industry and selling. Body packers hide illicit drugs in their bodies for different purposes. They conceal amounts of the drug to cross borders between countries and do the same in trials to hide them when they get caught by police; the latter usually pack small amounts and are called mini packers (Introna and Smialek 1989).

Cocaine and heroin are the most concealed drugs (Wetli et al. 1997; Kashani and Ruha 2004). Amphetamine and rarely cannabis are other reported drugs with a combination of drugs in several cases. The type of the drug depends on the drug market of the area and crossed

\footnotetext{
*Correspondence: alsaifd@yahoo.com

Center of Forensic and Legal Medicine, Eastern Province, Dammam, Saudi Arabia
}

borders (Heinemann et al. 1998; Gill and Graham 2002). Several other drugs were reported as lidocaine that is mixed with cocaine as it is cheaper and not detected (Nichols and Davis 1992). Diazepam liquid form and benzodiazepine were also reported (Wilcher 2011). In case of an expensive drug, the body of a dead packer is opened to retrieve the drug followed by disposal of the dead body (Wetli et al. 1997).

The number of packs in the case differs and can reach up to 57 packs (Ray et al. 2018). Different packaging materials are used and it depends on whether it was manual packing or machine sophisticated one (Bulstrode et al. 2002). Latex, condom, foil, greaseproof paper, and glass ampoules were all reported (Koehler et al. 2005). Machine packing uses special techniques to prepare packs that are both safe and more difficult to detect ((Cappelletti et al. 2019). 
Body packers use different cavities of the body to conceal packages. Stomach, rectum, vagina, and ear stuffing were all reported (Kashani and Ruha 2004; Cappelletti et al. 2019; Cappelletti and Piacentino 2018; MA and HP 1989). A rare case of concealing drug package behind the foreskin of an uncircumcised penis was reported (Wilcher 2011).

Simple investigations of suspected cases include urine and blood analysis. However, this can merely indicate the use of a drug rather than a leaking package. Radiological investigations are the second step in suspects and include ultrasound that is operatordependent (Klein et al. 2000) and plain abdominal $\mathrm{X}$-ray with specific signs including tic-tac, parallelism, and rosette signs (Ray et al. 2018). False negatives occur when packers use skills to mask the picture: by moving, drinking liquids to mask the densities, or taking constipating drugs to accumulate stool around the packages (Cappelletti et al. 2019; Abedzadeh et al. 2019; Cappelletti and Ciallella 2017). CT scan is the most useful technique but has the disadvantage of high radiation exposure (Heinemann et al. 1998). Drugs show different densities in CT with cocaine being less dense than fat, cannabis having the same bone density, and heroin having a density between that of fat and air (Abedzadeh et al. 2019).

Many body packers succeed in hiding the drug and reaching their goal, this is what makes it a desirable method of concealing an illicit drug. However, fatalities were reported since 1973 (Deitel and Syed 1973). A research in New York City found 50 cases with 5 fatalities, whereas a study in the UK found 180 cases with no fatalities (Bulstrode et al. 2002). Death occurs by leakage of the drug, intestinal obstruction (Hutchins et al. 2000), peritonitis (Wetli et al. 1997), perforation, or even obstruction of airways when rapidly engulfing the packages in mini packers (Introna and Smialek 1989). Death can be due to reasons unrelated to the body packing, either due to drug overdose or other causes of death with incidental finding of packages in the body during the autopsy.

In the past, surgery was the first-line management of body packers. Now, it became more conservative management with purgation or follow-up with close monitoring until expelled naturally, surgical intervention will be done only in cases with symptoms of leakage or intestinal obstruction (Klein et al. 2000; McCarron and Wood 1983; Benko et al. 2019; Beckley et al. 2009).

Up to the knowledge of authors, this is the first reported case of fatal body packer in Saudi Arabia and Arab countries, with methamphetamine and cannabis as the packed drugs.

\section{Case presentation}

A 37-year-old man was detained in prison when he developed pain and transferred to the hospital to be announced dead after a short time. The body was sent to the forensic medicine department to determine the cause of death.

Post mortem examination was done 7 days after death, when the legal order of autopsy was received by the forensic department. There were no signs of putrefaction and there were 2 irregular abrasions with underlying contusions over the forehead with dimensions of about $4 \times 5 \mathrm{~mm}$ and one irregular abrasion with underlying contusion over the mid-chest of about $5 \times$ $10 \mathrm{~mm}$. A foreign body was found in the mouth, made up of elastic rubber and plastic that were ruptured and found to be containing a white substance (Fig. 1). It was sent for toxicological analysis with a sample of subclavian blood. A urine sample could not be obtained.

A complete autopsy was performed and revealed brain petechial, edema of the lungs, and atheromatous narrowing of both coronary arteries. The abdominal autopsy showed 6 rounded foreign bodies in the stomach and 4 in the small intestine (jejunum and ilium), they were of different sizes with an average of $2 \mathrm{~cm}$ in their longest dimension, covered with a layer of elastic rubber and an inner layer of plastic cover (Figs. 2 and 3). Seven of them were filled with white powder, and three were filled with a grey dough-like substance (Figs. 4 and 5). All were sent for toxicological analysis.

Dissection of the heart showed coronary atherosclerosis that was confirmed by histological examination to be $80 \%$ occlusion of the left coronary and $75 \%$ occlusion of the right coronary.

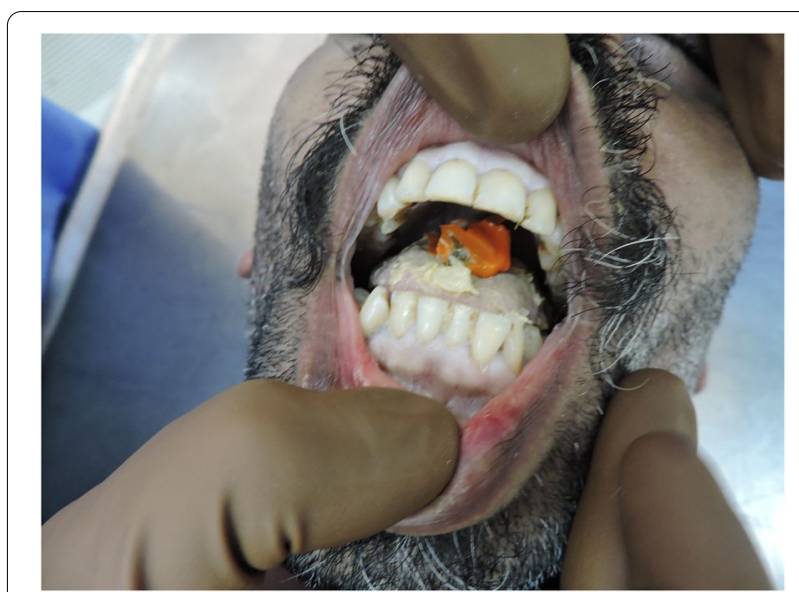

Fig. 1 Foreign body detected in the mouth, later found to be a ruptured rubber cover of a packed drug 


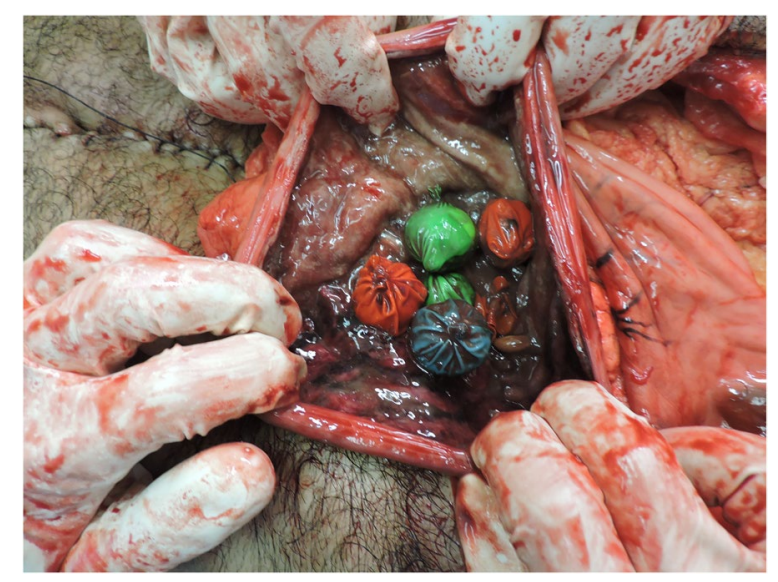

Fig. 2 Drug packs in the stomach

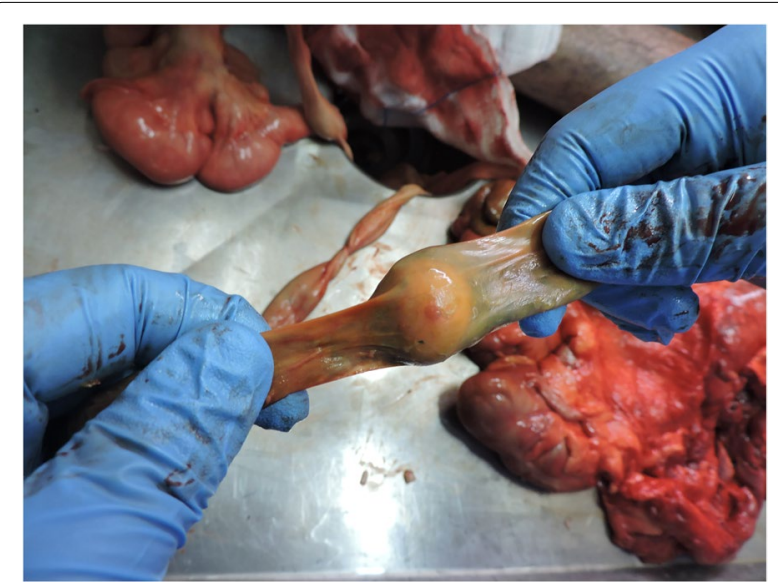

Fig. 3 A drug pack in the intestine

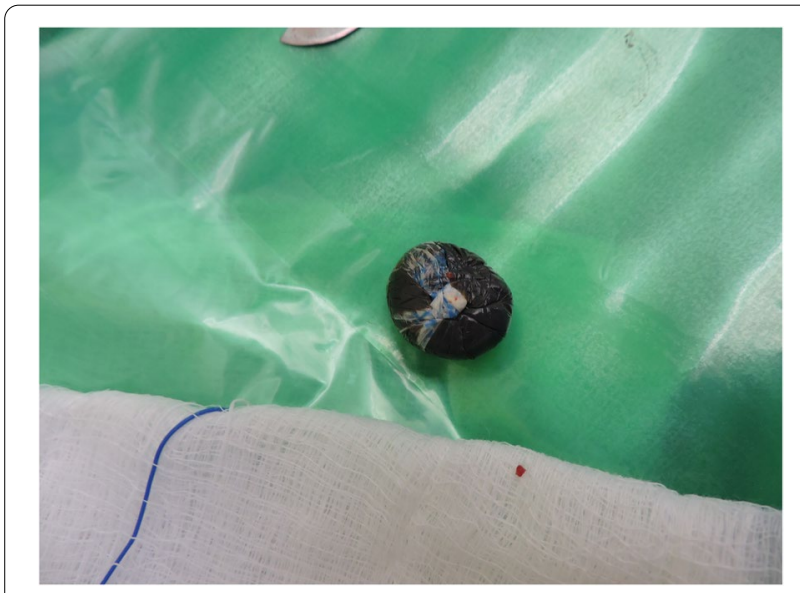

Fig. 4 A packed drug after removing the elastic rubber cover

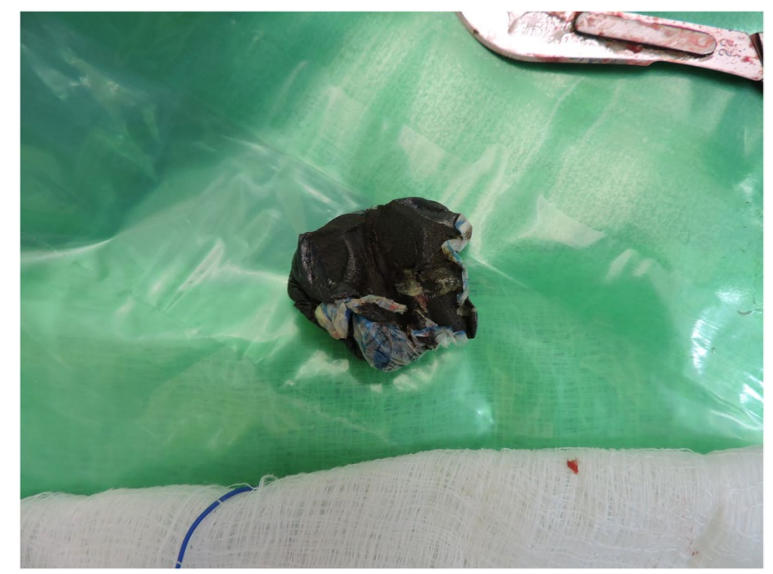

Fig. 5 Grey dough-like substance inside the pack

Toxicological analysis of the subclavian blood sample revealed a methamphetamine level of $3.66 \mathrm{mg} / \mathrm{L}$. Tetrahydrocannabinol and its metabolites were not detected.

The ruptured package in the mouth contained remnants of methamphetamine.

The rounded packages with white powder contained a total of $25 \mathrm{gm}$ of methamphetamine, and the packages with the grey dough-like substance contained a total of $19 \mathrm{gm}$ of tetrahydrocannabinol.

The cause of death was determined to be intoxication with methamphetamine.

\section{Discussion}

While body packing was reported in Arab countries previously (Abedzadeh et al. 2019), none of the reported cases were associated with fatality and this is the first reported case of a fatal body packer in Saudi Arabia and Arab countries. The victim in this case used the most common method of concealing the drugs: swallowing. Both amphetamine and cannabis that were used in this case are illicit drugs in the country and a person who is caught with them in his possession would suffer legal punishment. Amphetamine was reported in few cases as a cause of death in body packers (Takekawa et al. 2007), and cannabis body packing is rarely reported, with fatality in only two of the reported cases (Borgsteede et al. 2019; Spadari et al. 2011; Cawich et al. 2010; Barnett and Codd 2002). The low cost of such drugs compared to heroin and cocaine could explain the infrequency of packing them in the body, especially with knowing the risks of this act. The drugs were manually packed in 2 layers of elastic rubber and plastic which are considered poor materials that can resist tear and abrasion but not the acidity of the stomach, therefore it didn't tolerate the media 
inside the body and ruptured (Introna and Smialek 1989). Whether it ruptured in the stomach and regurgitated to the mouth or regurgitated and then ruptured in the mouth cannot be decided. However, all other packs were found intact in the stomach and small intestine.

Apart from airports where body packers are usually detected (Klein et al. 2000), they are frequently detected in places like prisons and mental health facilities. In our case, the detainee suffered pain in prison and he was transferred to the hospital where he died. Toxicological analysis of blood revealed $3.66 \mathrm{mg} / \mathrm{L}$ of methamphetamine, a level that is considered fatal (Logan et al. 1998; Molina and Jejurikar 1999; Hara et al. 1986). Postmortem redistribution could be used as an explanation for this high level as the sample was collected 7 days after death. However, in our case, the peripheral blood was collected and is considered more reflective of the level in the body at the time of death. In a study comparing methamphetamine levels in central blood from the heart and peripheral blood in 20 postmortem cases, it was found that the level is higher in the central blood and it was recommended to avoid interpreting the cause of death based on the central blood sample (Takekawa et al. 2007; Barnhart et al. 1999; Moriya and Hashimoto 2000). Moreover, the ruptured package in the mouth is evidence of the source of this high level. The coronary narrowing is severe and is considered fatal in an otherwise healthy individual with negative toxicological analysis; however, in this case, it could indicate chronic use of methamphetamine which can lead to death either directly through cardiac toxicity or by the sequel of its sympathomimetic effect on the heart. In this case, the presence of a rupture package containing methamphetamine in the mouth with a high level of it in the blood leads to the conclusion of death due to acute intoxication with methamphetamine (PS, BK. 2004; Schwarzbach et al. 2020).

\section{Conclusions}

This is a case of a detained person in jail who later was found to be a body packer concealing packages of methamphetamine and tetrahydrocannabinol in his body. $\mathrm{He}$ was unfortunate to have one of the packages ruptured leading to acute methamphetamine toxicity and death. Body packing syndrome should be suspected in prisons and mental health facilities and actions should be taken to save the life of the body packer and at the same time to prevent drug smuggling. Authorities could get important information from such cases including insights into the drug market, the advancement of the packaging methods, and the methods of drug concealment in the area.

\section{Authors' contributions}

All authors contributed to the writing and reviewing of the manuscript. All authors read and approved the final manuscript.

Funding

No funding

Availability of data and materials

All data pertaining to the case are available on request.

\section{Declarations}

\section{Ethics approval and consent to participate}

Ethical approval was obtained from the institutional review board at center of forensic and legal medicine, Dammam, Saudi Arabia (the committee's reference number is not applicable).

\section{Consent for publication}

Consent was obtained from the deceased next of kin.

\section{Competing interests}

All authors declare that they have no competing interests.

Received: 15 June 2021 Accepted: 15 November 2021

Published online: 03 December 2021

\section{References}

Abedzadeh AA, lqbal SS, Al Bastaki U, Pierre-Jerome C (2019) New packaging methods of body packers: role of advanced imaging in their detection. A case study. In Radiol Case Rep 14:627-633. https://doi.org/10.1016/j.radcr. 2019.03.002

Barnett JM, Codd G (2002) Sudden, unexpected death of a cannabis bodypacker, due to perforation of the rectum. J Clin Forensic Med 9(2):82-84. https://doi.org/10.1054/jcfm.2002.0558

Barnhart FE, Fogacci JR, Reed DW (1999) Methamphetamine--a study of postmortem redistribution. J Anal Toxicol 23(1):69-70. https://doi.org/10. 1093/jat/23.1.69

Beckley I, Ansari NA, Khwaja HA, Mohsen Y (2009) Clinical management of cocaine body packers: the Hillingdon experience. Can J Surg 52(5):417-421

Benko MJ, Abdulla SG, Cuoco JA, Dhiman N, Klein BJ, Guilliams EL, Marvin EA, Howes GA, Collier BR, Hamill ME (2019) Short- and long-term geriatric mortality after acute traumatic subdural hemorrhage. World Neurosurg 130:e350-e355

Borgsteede SD, Verwer PEB, Prins G, Wijma RA, de Keijzer K, Alsma J, Koch BCP (2019) Een bodypacker met cannabis [A body packer with cannabis]. Ned Tijdschr Geneeskd 163:D3403

Bulstrode N, Banks F, Shrotria S (2002) The outcome of drug smuggling by 'body packers'--the British experience. Ann R Coll Surg Engl 84(1):35-38

Cappelletti S, Ciallella C (2017) Commentary on false negative findings of plain radiographs in body packing. Clin Imaging 45:122-123. https://doi.org/ 10.1016/j.clinimag.2017.05.013

Cappelletti S, Piacentino D (2018) Body packing and intra-vaginal body pushing of cocaine: a not-so-rare event. Leg Med (Tokyo) 32:90-91. https:// doi.org/10.1016/j.legalmed.2018.03.008

Cappelletti S, Piacentino D, Ciallella C (2019) Systematic review of drug packaging methods in body packing and pushing: a need for a new classification. Am J Forensic Med Pathol 40(1):27-42. https://doi.org/10.1097/ PAF.0000000000000436

Cawich SO, Downes R, Martin AC, Evans NR, Mitchell DI, Williams E (2010) Colonic perforation: a lethal consequence of cannabis body packing. J Forensic Legal Med 17(5):269-271. https://doi.org/10.1016/j.jflm.2010. 02.012

Deitel M, Syed AK (1973) Intestinal obstruction by an unusual foreign body. Can Med Assoc J 109(3):211-212

Gill JR, Graham SM (2002) Ten years of "body packers" in New York City: 50 deaths. J Forensic Sci 47(4):843-846 
Hara K, Nagata T, Kimura K (1986) Forensic toxicologic analysis of methamphetamine and amphetamine in body materials by gas chromatography/ mass spectrometry. Z Rechtsmed 96(2):93-104. https://doi.org/10.1007/ bf00198625

Heinemann A, Miyaishi S, Iwersen S, Schmoldt A, Püschel K (1998) Body-packing as cause of unexpected sudden death. Forensic Sci Int 92(1):1-10. https://doi.org/10.1016/s0379-0738(97)00192-8

Hutchins KD, Pierre-Louis PJ, Zaretski L, Williams AW, Lin RL, Natarajan GA (2000) Heroin body packing: three fatal cases of intestinal perforation. J Forensic Sci 45(1):42-47

Introna F, Smialek JE (1989) The "mini-packer" syndrome. Fatal ingestion of drug containers in Baltimore, Maryland. Am J Forensic Med Pathol 10(1):21-24

Kashani J, Ruha AM (2004) Methamphetamine toxicity secondary to intravaginal body stuffing. J Toxicol Clin Toxicol 42(7):987-989. https://doi.org/10 1081/clt-200042554

Klein C, Balash Y, Pollak L, Hiss J, Rabey MJ (2000) Body packer: cocaine intoxication, causing death, masked by concomitant administration of major tranquilizers. Eur J Neurol 7(5):555-558

Koehler SA, Ladham S, Rozin L, Shakir A, Omalu B, Dominick J, Wecht CH (2005) The risk of body packing: a case of a fatal cocaine overdose. Forensic Sci Int 151(1):81-84. https://doi.org/10.1016/j.forsciint.2004.07.005

Logan BK, Fligner CL, Haddix T (1998) Cause and manner of death in fatalities involving methamphetamine. J Forensic Sci 43(1):28-34

MA B, HP M (1989) Ear packing in drug abusers. BMJ 298:214

McCarron MM, Wood JD (1983) The cocaine 'body packer' syndrome. Diagnosis and treatment. JAMA 250(11):1417-1420

Molina NM, Jejurikar SG (1999) Toxicological findings in a fatal ingestion of methamphetamine. J Anal Toxicol 23(1):67-68. https://doi.org/10.1093/ jat/23.1.67

Moriya F, Hashimoto Y (2000) Redistribution of methamphetamine in the early postmortem period. J Anal Toxicol 24(2):153-155. https://doi.org/10. 1093/jat/24.2.153

Nichols GR, Davis GJ (1992) Body packing with a twist. Death of a salesman. Am J Forensic Med Pathol 13(2):142-145. https://doi.org/10.1097/00000 433-199206000-00013

PS, BK. (2004) Knight's forensic pathology, 3rd edn. Hodder Education Publishers, London

Ray A, Nayan A, Katariya K, Sharma SK (2018) Body packer syndrome: a radiological denouement! J Emerg Med 55(2):260-263. https://doi.org/10. 1016/j.jemermed.2018.04.005

Schwarzbach V, Lenk K, Lauf U (2020) Methamphetamine-related cardiovascular diseases. ESC Heart Failure 7:407-414. https://doi.org/10.1002/ehf2. 12572

Spadari M, Canioni D, Gregoire E, Drouet G, Bourdon JH, Arditti J, Micallef J (2011) Cannabis body packing: two case reports. Clin Toxicol (Phila) 49(9):862-864. https://doi.org/10.3109/15563650.2011.623679

Takekawa K, Ohmori T, Kido A, Oya M (2007) Methamphetamine body packer: acute poisoning death due to massive leaking of methamphetamine. J Forensic Sci 52(5):1219-1222. https://doi.org/10.1111/j.1556-4029.2007. 00518.x

Wetli CV, Rao A, Rao VJ (1997) Fatal heroin body packing. Am J Forensic Med Pathol 18(3):312-318. https://doi.org/10.1097/00000433-19970 9000-00018

Wilcher G (2011) Drug-related deaths with evidence of intracorporeal drug concealment at autopsy: five case reports. Am J Forensic Med Pathol 32(4):314-318. https://doi.org/10.1097/PAF.0b013e3181efbc09

\section{Publisher's Note}

Springer Nature remains neutral with regard to jurisdictional claims in published maps and institutional affiliations. 